\title{
Features of Russian regulatory framework governing cathodic protection of heating networks against external corrosion in the ground
}

\author{
Aleksandr Kalyutik ${ }^{1}$, Vladimir Kiselev ${ }^{1}$, Evgenij Ruzich, ${ }^{2, *}$, and Andrey Kibarin ${ }^{3}$ \\ ${ }^{1}$ Peter the Great St. Petersburg Polytechnic University, St. Petersburg, Russian Federation \\ ${ }^{2}$ NII “GIRICOND”, St. Petersburg, Russian Federation \\ ${ }^{3}$ Almaty University of Power Engineering and Telecommunications, Almaty, Kazakhstan
}

\begin{abstract}
A comparative analysis of domestic and foreign documents governing the design of cathodic protection systems has been carried out. The main parameters for evaluating the effectiveness were selected: "protective current density", "protective current value" and "indicators characterizing the degree of protection against corrosion in the presence of cathodic protection". As a result, the need for improving the domestic system for designing cathodic protection installations was established. First of all, attention should be paid to the decrease in protective current, protective current density and criteria for determining the need for cathodic protection.
\end{abstract}

\section{Introduction}

Corrosion resistance and price are important factors in design, operation and sanation of pipelines and other underground metal structures (PMS) of various types [1]. Corrosion is being related as both economic and technical problem, since it causes possible losses of assets, and requires technical measures aimed at reducing the rate of metal destruction [2-4]. This fact is reflected in clause 1.4 of GOST 9.602-89 at the legislative level. "Designing a project of underground metal structures construction, simultaneously a project to protect them against corrosion should be developed." Clause 1.11 of the same regulatory document states: "The means of protecting underground metal structures from corrosion are selected based on the type of construction, laying conditions, data on the risk of corrosion and the required service life of the structure on the basis of feasibility study .... The last clause, unfortunately, was abolished in 1995. Thus, both GOST 51164-98 and GOST 9.602-2005 (these normative documents are still in effect), demonstrate a unified approach to the issue of implementing anticorrosive measures. They (anticorrosive measures) are determined by regulatory documents, and the choice of the most effective option is not required [5-9]. Moreover, the current instructions, particularly "Standard Instruction for the Protection of Pipelines of Heating networks from External Corrosion" and the "Instruction for the Protection of Urban Underground Pipelines from
Corrosion", created on the basis of the Soviet normative act "Instruction for the Protection of Urban Underground Pipelines from Corrosion ", reproduce the same outdated ideology of anticorrosion protection. The aim of this article is to determine main directions of modernization of these normative documents, first of all, in the field of improving cathodic protection against corrosion.

\section{Methods}

At present, the protection of heat pipelines from corrosion is carried out on the basis of RD 153-34.020.518-2003 ("Typical instructions for protecting pipelines of heating networks from external corrosion"). We will examine main provisions of this normative document, especially with regard to the economic effectiveness of the technical solutions adopted for cathodic protection of heating networks or joint cathodic protection of communications for various purposes, which is closely related to the magnitude of the protective current. To narrow this very broad area of research, we restrict ourselves to the consideration of networks of non-channel gasket. In this case, one of the main criteria determining the overall scope of work on their cathodic protection is possibility (danger) of external corrosion of underground pipelines of heating networks, the requirements for their electrochemical protection (ECP) and the magnitude of the protective current. We will focus on the analysis of these in more detail in the following sections of this article.

\footnotetext{
* Corresponding author: rouzith@mail.ru
} 


\section{Results and discussion}

\subsection{Criteria for the necessity of cathodic protection of newly constructed and reconstructed pipelines of heating networks of non-channel gasket}

In accordance with clause 3.1 of the Regulations RD 153-34.0-20.518-2003: "For pipelines of heating networks of non-channel gasket, the criteria for the risk of corrosion are the following:

- high corrosive soil aggressiveness;

- dangerous influence of a wandering DC;

- dangerous effect of alternating current. "

Clause 3.2 of the same instruction describes the method for determining the index of "high corrosion aggressiveness of the soil": "Corrosive aggressiveness of the soil with respect to carbonaceous and low-alloy steels from which heat networks are made is characterized by two indicators:

- specific electrical resistance of soil (UES), determined in the field;

- UES of soil, determined in laboratory conditions.

If one of the indicators shows high aggressiveness of the soil (see Table 1), then the soil is considered aggressive and the determination of the second indicator is not required. "

In turn, clauses 3.3 and 3.4 describe methods for determining the indices "dangerous influence of a wandering direct current" and "dangerous influence of an alternating current".

Table 1. Corrosive aggressiveness of the soil applied to carbonaceous and low-alloy steels

\begin{tabular}{|c|c|}
\hline $\begin{array}{c}\text { Corrosion aggressiveness of } \\
\text { the ground }\end{array}$ & $\begin{array}{c}\text { Specific electric } \\
\text { resistance of ground, } \\
\text { Ohm·m }\end{array}$ \\
\hline Low & Over 50 \\
Average & 20 to 50 \\
High & Less than 20 \\
\hline
\end{tabular}

Section 7 of Instruction RD 153-34.0-20.518-2003 has the logical continuation of this topic with regard to the cathodic protection of heat networks. In clause 7.1.1 of this section, which specifies the requirements for ECP for pipelines of heating networks of non-channel gasket, the following is stated: "Cathodic polarization of pipelines of heating networks of non-channel gasket is mandatory:

-when laying in soils with high corrosive aggressiveness (protection from soil corrosion);

-in the presence of a dangerous effect of constant wandering currents and alternating currents (for newly constructed pipelines - in the presence of constant stray currents in the ground).

Correct assessment of flexibility of the above criteria determining necessity for ECP to protect heating networks against corrosion is possible with a certain comparison base. We will use for this purpose normative documents and a number of other technical materials regulating cathodic corrosion protection processes in
Germany, for example, the reference [10] Section 3.1.5 "Beurteilung der Korrosionsgefahr" that examines the main criteria for the advisability of cathodic protection of ICP from corrosion. In this case, in accordance with [10], the following values should be used to estimate corrosion risks:

- specific resistance and homogeneity of the soil;

- the potential of the object / ground and the possible influence of stray currents;

- resistance to spreading of underground metal structures.

However, as the next paragraph of this text shows, these indicators are considered integrally with their role in the corrosion process. In this case, the regulating document states: "Each individual measurement result is associated with a certain characteristic number. If the sum of these characteristic numbers is 18 or more, then the implementation of cathodic protection is necessary".

In addition to considering the value of each indicator, this system has a number of other features. For example, in Section 3.1.5.1 of the reference book "Bodenwiderstand und Homogenität des Bodens" [10], contains similar to Russian standard for estimating soil resistivity and also has method of evaluating the heterogeneity of the soil according to its electrical resistance. It should be noted that in German version indicator showing necessity for cathodic protection through measuring the specific electrical resistance of the soil significantly differs from the corresponding Russian standard. For example, in accordance with clause 3.2 of the Regulations RD 153-34.0-20.518-2003, the corrosive aggressiveness of the ground with respect to carbonaceous and low-alloy steels is recognized as high if soil electrical resistivity is less than $20 \Omega \mathrm{m}$. Similar norm of German regulation requires less than $100 \mathrm{Ohm} \cdot \mathrm{m}$ electrical resistance of the soil.

Taking into consideration all the above we can identify significant difference between German and Russian norms in terms of flexibility, which automatically leads to a wider distribution of cathodic protection systems for underground metal communications against corrosion in Germany compared with Russian Federation.

A similar situation is observed if we analyze the influence of permanent stray currents on underground non-channel gasket heating networks. Indeed, clause 3.3 section 3 "Criteria (signs) of the danger of external corrosion of underground pipelines of heating networks" Regulations RD 153-34.0-20.518-2003 is the following: "The possibility of dangerous influence of a stray AC current on the operation of underground steel pipelines of heating networks is determined by the presence of a variable in sign and magnitude potential shift of the pipeline with respect to its stationary potential (alternating zone) or by the presence of only a positive shift of the potential varying in magnitude (anode zone). For newly built heating pipelines is determined by the presence of stray currents in the ground. "This clause to some extent corresponds with section 3.1.5.2 "Objekt/Boden-Potential und Streustrromeinflusse" of the handbook [10]. However, in the latter case, as a 
prerequisite for measuring potentials, it is necessary to remove the contacts of the object under consideration, having small electrical resistances, from other grounded objects. Obviously, this circumstance results on the one hand in a sharp decrease in current consumption by cathodic protection installations, and on the other hand contributes to a more even distribution of the protective potential on the protected structure. Thus, the probability of an insufficient protective potential of PMS reduces sharply. An additional positive effect of this measure is a decrease in the magnitude of stray currents in the area of cathodic protection installation.

It should be noted that set of measures presented in clause 3.1.5.3 "Ausbreitungswiderstand" of the handbook [10] has the same focus, considering low resistance of spreading of the protected object, which is usually caused by defects in the insulation coating, as a factor influencing decision of the need of UMC cathodic protection.

Regarding the necessity of cathodic protection in the presence of AC stray currents, clause 3.4 "Criteria (signs) of the danger of external corrosion of underground pipelines of heating networks", Regulations RD 153-34.0-20.518-2003 was developed, which is formulated as follows: "Possibility of dangerous influence of alternating current on steel underground pipelines of heating networks is determined by the shift of the average value of the pipeline potential to the negative side by no less than $10 \mathrm{mV}$, in relation to the stationary potential, or by the presence of an AC current with a density of more than $1 \mathrm{~mA} / \mathrm{cm} 2$ (10 A / m2) on the auxiliary electrode. A similar norm is also found in German regulative documents which is listed in the handbook [10, pp. 187 - 190]

\subsection{Requirements for ECP pipelines for heating networks of non-channel gasket}

In accordance with clause 7.1.2 of the Regulations for protection of thermal networks from external corrosion [2]: "In order to protect against soil corrosion, the cathodic polarization of the pipelines of the nonchannel gasket heating networks should be carried out in such a way that the potential difference between the pipeline and the MES is within $-1.1 \mathrm{~V}$ to $-2.5 \mathrm{~V}$... ".

Aforementioned normative document sets similar requirements for cathodic protection against external corrosion caused by alternating stray currents (clause 7.1.5 of RD Regulations 153-34.0-20.518-2003). There is a similar situation for determining the requirements for ECP pipelines of non-channel gasket heating networks in the presence of constant stray currents. In this case, in accordance with clause 7.1.3 [2] "When protecting pipelines from corrosion under the influence of constant stray currents, the cathodic polarization must be carried out in such a way that the anode and alternating zones are not present on the pipelines." In all these cases, the potentials are measured with their ohmic component. Consequently, it can be argued that in Russia a rather archaic criterion is used for estimating the degree of cathodic protection of PMS, including a joint measurement of the polarization and ohmic potentials, which, as we shall see later, has a very negative effect on the accuracy of determining the protective current of underground metal structures.

The requirements for ECP, defined by the regulatory documents of the Federal Republic of Germany, in particular DIN 30676 "Planung und Anwendung des Kathodische Korrosionsschutzes für den Außenchutz" [11] are much less flexible and require the use of the concept of "polarization potential".

Indeed, in clause 3.1 of DIN 30676 it is indicated: «The protective potential is the boundary value of the potential $U_{s}$, at which the corrosion rate becomes technically so negligible that corrosion damage becomes impossible. Therefore, the criterion for corrosion protection can be written as follows:

$$
U \leq U_{S}
$$

where, $U-$ is potential (without an ohmic component) of considered underground metal structure. Subsequently, in clause 3.1 of DIN 30676 in Table 1, specific values of the protective potentials Us are given, which are in good agreement with GOST 9.602-2005. In addition note to clause 3.1 of DIN 30676 states the need to limit the protective potential on the negative side, which is due to the need to preserve the protective coating of the pipeline

\subsection{Determination of the protective current for pipelines of heating networks of non- channel gasket}

The first step in determination of the protective current for pipelines of heating networks of a non-channel gasket will be the analysis of Appendix $M$ of the Instruction RD 153-34.0-20.518-2003 "Recommendations for determining the calculation method of ECP parameters for newly constructed and reconstructed heating networks of channel and nonchannel gaskets in the joint protection of underground structures for various purposes."

Clause 6 of this appendix reads: "The average current density necessary for the protection of pipelines is determined by the formula:

$$
i=30-(100 b+128 c+3 e+0,6 f+5 \rho) \cdot 10^{-3} \mathrm{~mA} / \mathrm{m}^{2},
$$

where, $\rho$ - electrical resistivity of soil Ohm meter».

In their turn, quantities $b, c, e, f$ included in equation (2) are determined in accordance with clauses 4 and 5 of appendix $\mathrm{M}$ in the following way:

1. Appendix M, clause 4. "The proportion of the surface area of each of the pipelines in the total mass of underground structures, $\%$, is determined by the formulas:

Pipelines of heating networks

$$
c=\frac{S_{m e n}}{\sum S},
$$

Water pipelines

$$
b=\frac{S_{b}}{\sum S},
$$

Gas pipelines 


$$
g=\frac{S_{g}}{\sum S} .
$$

2. Appendix F, clause 5. "The surface area of each of the structures per unit surface area (protection zone), $\mathrm{m}^{2} / \mathrm{ha}$, is defined by the formulas:

Pipelines of heating networks

$$
f=\frac{S_{m e n}}{S_{m e p}},
$$

Water pipelines

$$
e=\frac{S_{b}}{S_{m e p}},
$$

Gas pipelines

$$
d=\frac{S_{g}}{S_{m e p}} .
$$

where, $S_{\text {ter }}$ - area of the territory occupied by the protectable constructions, ha.

In turn, in accordance with clause 3 of Appendix M "The total surface area of all jointly protected pipelines, including newly constructed (or reconstructed pipelines of heating networks of the non-channel gasket), electrically connected to each other, is equal to:

$$
\sum S=S_{\text {men }}+S_{g}+S_{b} .
$$

The same point specifies individual values of the equation (M.2) "the surface of the pipelines of the heating networks of the non-channel gasket is added to the surface of the water pipelines, so here and below the value of $S_{\text {tep }}$ refers to the operating pipelines of the heating networks of the channel gasket".

Analysis of the formula (M.9, clause 6) and clauses 3, 4 and 5 of Appendix M of RD Regulations 153-34.020.518-2003, defining the content of clause 6 allows us to draw the following conclusions:

1. Due to the fact that the instructions doesn't have physically grounded principles that served as the basis for the derivation of the formula (2), then its creative application based, for example, on the criteria "reduced costs" or "achievement of the protective potential" becomes practically impossible.

2. According to the formula (2), the density of the protective current is a function of the electrical resistivity of soil, which directly contradicts the reference [10, p. 93] and the physical meaning of the ongoing electrochemical process using the concept of "polarization potential" as a criterion for the presence of electrochemical protection of PMS. Indeed, in this case, with increasing resistivity of the soil and, for example, in the presence of insulation defects of the same value, in accordance with [10, p. 213], it is necessary to increase the converter power by increasing its output voltage while maintaining the protective current, rather than decrease the value of the protective current. However, as we noted earlier, instruction (RD 153-34.0-20.518-2003) applies "polarization potential with an ohmic component" criterion as a measure of PMS corrosion protection, which makes the formula (2) formally suitable for use. At the same time, it should be noted that with increasing electrical resistivity of soil, and other parameters being equal, there will be a drop in the protective polarization potential of the PMS and, consequently, a decrease in their level of corrosion protection.

3. The instructions uses the averaged value of electric resistivity of the soil (item 7.8.4), but there is no way of calculating it.

4. According to the formula (2), the density of the protective current is a function of the area of the land on which it is located, as well as the ratio of different types of pipelines. This statement simply contradicts the physical meaning of the cathodic polarization process that is confirmed by an experiment determining the density of the protective current [10, p. 82].

Particular attention should be paid to clause 7 of Appendix M of the Instruction, which says: "If the value of the average protective current density obtained by the formula (2) is less than $10 \mathrm{~mA} / \mathrm{m}^{2}$, then in further calculations one should take $\mathrm{mA} / \mathrm{m}^{2}$." In this case, the Legislator deliberately excludes modern PMS isolation $[10$, p. 82] and limits the possible reduction in the density of the protective current, thus stimulating the increased costs of creating a cathodic protection system.

In turn, the values of the protective current, determined by the regulatory documents of the Federal Republic of Germany, in particular DIN 30676 "Planung und Anwendung des Kathodische Korrosionsschutzes für den Außenchutz" [11] are much less than that provided for in Russian regulatory documents. Let's illustrate this thesis with a quote from clause 5.3.11 "Determination of the protective current value" DIN 30676: “...The new protection facilities laid in the ground have an average protective current density of 30 $\mu \mathrm{A} / \mathrm{m}^{2}$ with bitumen insulation, and $3 \mu \mathrm{A} / \mathrm{m}^{2}$, respectively, with polyethylene insulation...” A simple comparison of the indicated densities of the protective current with clause 7 of Appendix M of Instruction RD 153-34.0-20.518-2003, shows that even the minimum values of the protective current can differ from the corresponding average values by approximately thousand times. An immediate consequence of this circumstance is the overestimated values of the protective current in cathodic protection systems. Thus, for example, when designing cathodic protection facilities in accordance with clause 13 of Appendix P of the Instruction for the Protection of Urban Underground Pipelines against Corrosion RD 153-39.4-091-01, it is assumed that "... the current value of one cathode station can approximately be assumed to be $25 \mathrm{~A} "$.

Similar values typical for cathodic protection installations in Germany are usually less than 10 amperes with a much larger area of the protected surface of the underground pipeline [10, p. 162]. Explicitly overestimated values of protective currents in cathodic protection practice in Russia made it necessary to analyze this phenomenon and develop measures to reduce them, which caused a whole series of works, specifically devoted to this problem [12-16]. 


\section{Conclusion}

Paper provides comparative analysis of basic regulations governing design of systems of cathodic protection of underground metal structures against corrosion based on both Russian and international materials [17-21]. The following basic parameters for evaluation of cathodic protection system performance are accepted: "need for applying cathodic protection systems", "values characterizing security of underground metal structures against corrosion in the presence of electrochemical protection", "density of protective current" and "magnitude of protective current". As a result of the analysis, the following conclusions are drawn:

1. The parameter "Criteria for the necessity of using cathodic protection systems" is more flexible than, for example, similar parameter used in the German regulatory documentation, which leads to a wider distribution of cathodic protection systems in Germany, compared to Russian practice.

2. The parameter "values characterizing the protection of underground metal structures against corrosion in the presence of their electrochemical protection", used in the normative documentation of Germany suggests the measurement of polarization potentials. In Russian practice, in this case, the polarization potential with an ohmic component is measured, which makes the measurement data less correct, especially with a high specific resistivity of the ground.

3. The parameters "protective current density" and "protective current value" calculated using Russian regulatory documentation significantly exceed similar parameters obtained using German regulatory documents. This circumstance, as shown in this paper, is largely due to the use of preparatory measures in the German practice of designing cathodic protection, including, first of all, ensuring the high longitudinal conductivity of the protected structure, high quality of insulation and the absence of contacts with other grounded metal structures.

\section{References}

1. D. Kuang, Y.F. Cheng, Study of cathodic protection shielding under coating disbondment on pipelines, Corrosion Science 99, 249-257 (2015)

2. X. Chen, X.G. Li, C.W. Du, Y.F. Cheng, Effect of cathodic protection on corrosion of pipeline steel under disbanded coating, Corrosion Science 51, 2242-2245 (2017)

3. S. Qian, Y.F. Cheng, Accelerated corrosion of pipeline steel and reduced cathodic protection effectiveness under direct current interference, Construction and Building Materials 148, 675-685 (2017)

4. L.Y. Xu, Y.F. Cheng, Experimental and numerical studies of effectiveness of cathodic protection at corrosion defects on pipelines, Corrosion Science 78, 162-171 (2014)
5. V. G. Kiselev, A. A. Kalyutik, A. V. Fedyukhin, S. O. Makoev, Main trends in increasing technical and economic efficiency of underground power pipelines cathodic protection. IOP Conference Series: Earth and Environmental Science 288(1), 012098 (2019)

6. V. G. Kiselev, A. A. Kalyutik, E. N. Rouzich. Influence of the soil electrical conductivity in the area of the underground pipeline on energy efficiency of the cathodic protection. MATEC Web of Conferences 245(1), 07015 (2018)

7. A. Belyaev, A. Grishchenko, A. Lobachev, V. Polyanskiy, D.Tretyakov, Discrete and continual approaches to the description of random microstructure of materials. AIP Conference Proceedings 2053, 020001 (2018)

8. I. Anikina, V. Suslov, Influence of heat pumps inclusion in deaeration scheme of heating network make-up water on the operating modes of the TPP. MATEC Web Conf. 245, 15004 (2018)

9. D.Tretyakov, A. Belyaev, A. Galyautdinova, V. Polyanskiy, D. Strekalovskaya, Investigation of the corrosion process and destruction of metals by using acoustodamage method, E3S Web Conf. 121, 01017 (2019)

10. Ulrich Bette, Wolfgang Vesper. Taschenbuch für den kathodischen Korrosionsschutz. Vulkan-Verlag Essen 367 (2005)

11. DIN 30676: Planung und Anwendung des kathodischen Korrosionsschutzes für den Außenchutz, BeuthVerlag, Berlin (1983)

12. A. A. Tsynaeva, Cathode protection systems of cross-country pipelines, Procedia Engineering 111, 777-782 (2015)

13. I. M. Gadala, Numerical simulations of soil physicochemistry and aeration influences on the external corrosion and cathodic protection design of buried pipeline steels. Materials and Design 97, 287299 (2016)

14. Kiselev, V. G. Influence of the electric double-layer capacitance at the rate of corrosion at the phase interface, Corrosion Reviews 35 (1), 47-51 (2017)

15. M. Mitolo, Interactions Between Cathodically Protected Pipelines and Grounding Systems. IEEE Transactions On Industry Applications 52(5), 36943698 (2016)

16. I. Anikina, V. Sergeev, N. Amosov, M. Luchko., Use of heat pumps in turbogenerator hydrogen cooling systems at thermal power plant. International Journal of Hydrogen Energy 42(1), 636-642 (2017)

17. E. V. Moskvicheva, Method of Corrosion Prevention in Steel Pressure Pipelines in Sewerage Systems, Procedia Engineering 150, 2381-2386 (2016)

18. A. Alkhimenko, Corrosion testing of experimental steels for oilfield pipelines, E3S Web Conf. 121, 01001 (2019)

19. D. Tretyakov, A. Belyaev, A. Galyautdinova, V. Polyanskiy, D. Strekalovskaya, Investigation of the 
corrosion process and destruction of metals by using acoustodamage method, E3S Web Conf. 121, 01017 (2019)

20. I. Akhmetova, N. Chichirova, O. Derevianko, Revisiting heat losses calculation at district heating network, International Journal of Civil Engineering and Technology 8(12), 694-702 (2017)

21. P. Ovchinnikov, A. Borodinecs, Strelets, K. Utilization potential of low temperature hydronic space heating systems: A comparative review, Building and Environment 112, 88-98 (2017) 